\title{
Brain metabolic differences between temporal lobe epileptic seizures and organic non-epileptic seizures in postictal phase: a retrospective study with magnetic resonance spectroscopy
}

\author{
Dongbao Liu ${ }^{1 \#}$, Yonggui Yang ${ }^{2 \#}$, Dicheng Chen ${ }^{1}, \mathrm{Zi} \mathrm{Wang}^{1}$, Di Guo ${ }^{3}$, Lijun Bao ${ }^{1}$, Jiyang Dong ${ }^{1}$, \\ Xin Wang ${ }^{1}$, Xiaobo $\mathbf{Q u}^{1 \wedge}$ \\ ${ }^{1}$ Department of Electronic Science, Biomedical Intelligent Cloud R\&D Center, Fujian Provincial Key Laboratory of Plasma and Magnetic Resonance, \\ National Institute for Data Science in Health and Medicine, Xiamen University, Xiamen, China; ${ }^{2}$ Department of Radiology, The Second Affiliated Hospital \\ of Xiamen Medical College, Xiamen, China; ${ }^{3}$ School of Computer and Information Engineering, Xiamen University of Technology, Xiamen, China
}

"These authors contributed equally to this work.

Correspondence to: Xiaobo Qu. Department of Electronic Science, Biomedical Intelligent Cloud R\&D Center, Fujian Provincial Key Laboratory of Plasma and Magnetic Resonance, National Institute for Data Science in Health and Medicine, Xiamen University, Xiamen 361005, Fujian Province, China. Email: quxiaobo@xmu.edu.cn.

\begin{abstract}
Magnetic resonance spectroscopy (MRS) is employed to investigate the brain metabolites differences between patients with temporal lobe epileptic seizures (TLES) and organic non-epileptic seizures (ONES) that appear to be epileptic seizures. Twenty-three patients with TLES and nine patients with ONES in postictal phase underwent MRS examinations on a clinical $1.5 \mathrm{~T}$ system, with 15 healthy controls in comparison. Statistical analyses on the ratios of brain metabolites were performed using the MannWhitney $U$ test with age as a covariate. The results showed that $\mathrm{N}$-acetyl-aspartate/Creatine (NAA/Cr) ratio of patients with TLES was statistically different from that of patients with ONES in postictal phase, i.e., TLES $1.422 \pm 0.037$, ONES $1.640 \pm 0.061, \mathrm{P}=0.012$ in left temporal pole, while TLES $1.470 \pm 0.052$, ONES $1.687 \pm 0.084, \mathrm{P}=0.023$ in the right temporal pole. Besides, compared with healthy controls, patients with TLES in postictal phase present significant differences in ratios of NAA/Cr, $\mathrm{N}$-acetyl-aspartate/ Choline (NAA/Cho) and NAA/(Cho + Cr). Experimental results demonstrate that NAA/Cr can be used to discriminate TLES from ONES, which has not been found in the references to the best of our knowledge. Although a prospective controlled validation is needed in the future, this retrospective study reveals that MRS may provide useful metabolites information to facilitate the epilepsy diagnosis.
\end{abstract}

Keywords: Metabolites; magnetic resonance spectroscopy (MRS); temporal lobe epileptic seizures (TLES); organic non-epileptic seizures (ONES); brain

Submitted Oct 13, 2020. Accepted for publication Mar 22, 2021.

doi: $10.21037 /$ qims-20-1147

View this article at: http://dx.doi.org/10.21037/qims-20-1147

\section{Introduction}

As the most common type of drug-resistant epilepsy in clinics, temporal lobe epilepsy (TLE) is primarily accompanied by temporal cortex lesions $(1,2)$. Generally, the drug-refractory epilepsy can be effectively treated by surgical resection of epileptogenic focus (3). However, distinguishing temporal lobe epileptic seizures (TLES) from

\footnotetext{
^ ORCID: 0000-0002-8675-5820.
} 

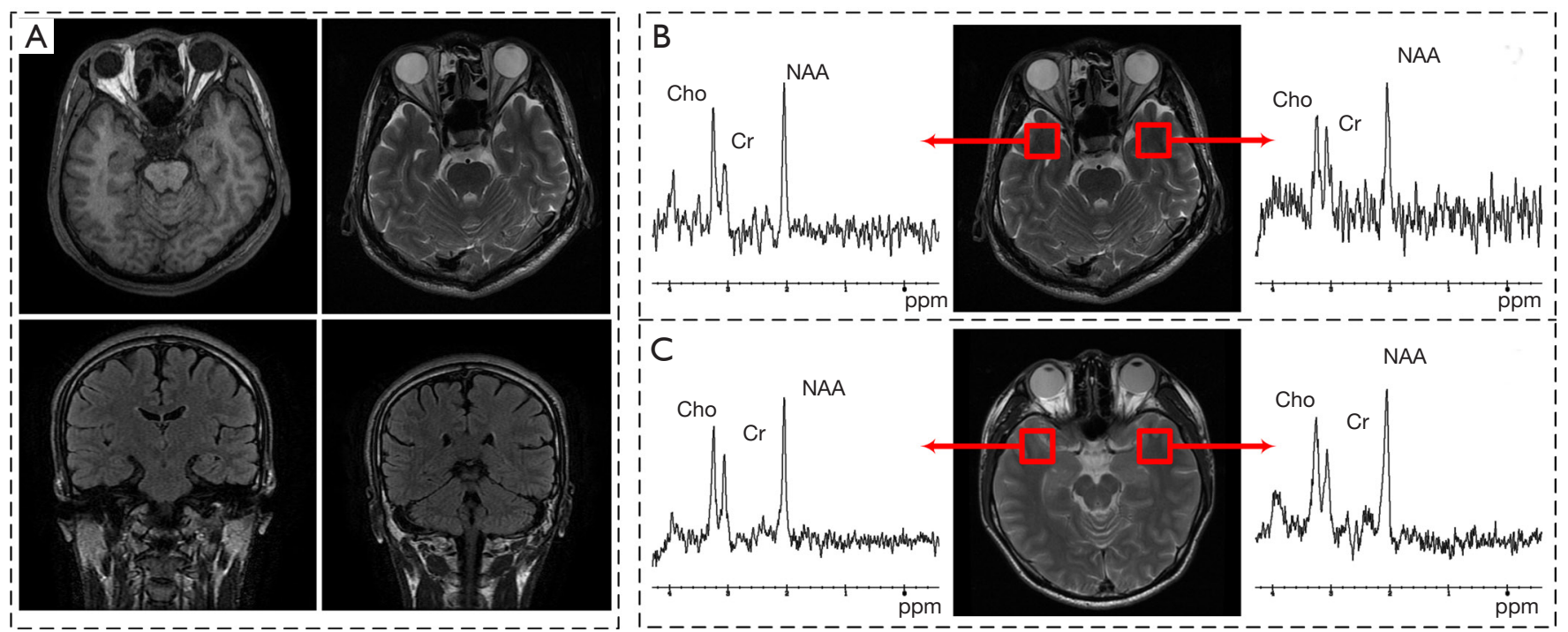

Figure 1 Negative craniocerebral MRI of patient M (A): a clear boundary between gray and white matter without significant abnormal signals in the brain parenchyma and hippocampal, no expansion of the ventricular system, normal size, and shape of the cistern and sulci. MRS of patient $M(B)$ and healthy control $N(C)$.

organic non-epileptic seizures (ONES) during diagnosing epilepsy (4) remains as a challenging task. ONES is regarded as paroxysmal events that will be mistaken for epilepsy, but is actually not triggered by the epileptic disorder. Instead, it describes a symptom for a diverse group of disorders, including a wide range of conditions, e.g., hypertension, cerebrovascular disease of acute onset, migraine, transient ischemic attack, syncope, dizziness vertigo (4-6).

When patients behave abnormally, their performances are easily reminiscent of epilepsy. Therefore, seeking a scientifically accurate diagnosis and treatment is urgently called for. During TLES, the patients have impairment of consciousness, sudden limb tic, etc. The seizures last 30 seconds to a couple of minutes. And these conditions also exist in patients with ONES (4). At the same time, the correct diagnosis and classification of epileptic seizures depend highly on the extent and quality of evidence acquired at the time of initial diagnosis and additional evidence accumulated over time. At present, the diagnosis methods of epilepsy include magnetic resonance imaging (MRI) and video electroencephalography (V-EEG) (7). The brain MRI might reveal a structural cause for epilepsy, such as mesial temporal sclerosis, but $20 \%$ to $30 \%$ of patients with TLES demonstrate no MRI abnormalities (8). V-EEG monitoring may be time-consuming and have limited spatial sampling (9). The average duration of this process is three days (standard deviation \pm 1 , ranging from 1 to 9 days) to obtain an accurate diagnosis (10), and interictal epileptiform discharges alone cannot reliably distinguish epileptic seizures from nonepileptic events in all cases (11).

Planned magnetic resonance spectroscopy (MRS) study of patients with frequent or continuous partial seizures may offer a unique opportunity to discover the brain metabolic pattern during ictal events. Figure 1 shows that MRS, which can reveal the metabolic abnormalities in brain tissues of patients who have normal MRI (12) (Figure 1A,B), is a potent tool to locate the seizure focus of epileptic patients by a quantitative analysis of the proton metabolite concentration in the brain (13). A previous study showed that the main contribution of MRS for diagnosis of epilepsy came from $\mathrm{N}$-acetyl-aspartate (NAA) (1), Creatine phosphate (Cr) (13), and Choline containing compound (Cho) (14). In this work, we will compare the metabolite ratios differences between TLES patients, ONES patients and healthy controls, expecting to assist identification and classification of TLES and ONES in the early stage. We did this work in a retrospective way.

\section{Methods}

\section{Subjects}

Under the authorization of the Medical Ethics Committee of the Second Hospital of Xiamen City, the subjects signed informed consent forms in this examination. The subjects included 23 patients with clinically diagnosed TLES (15 
A

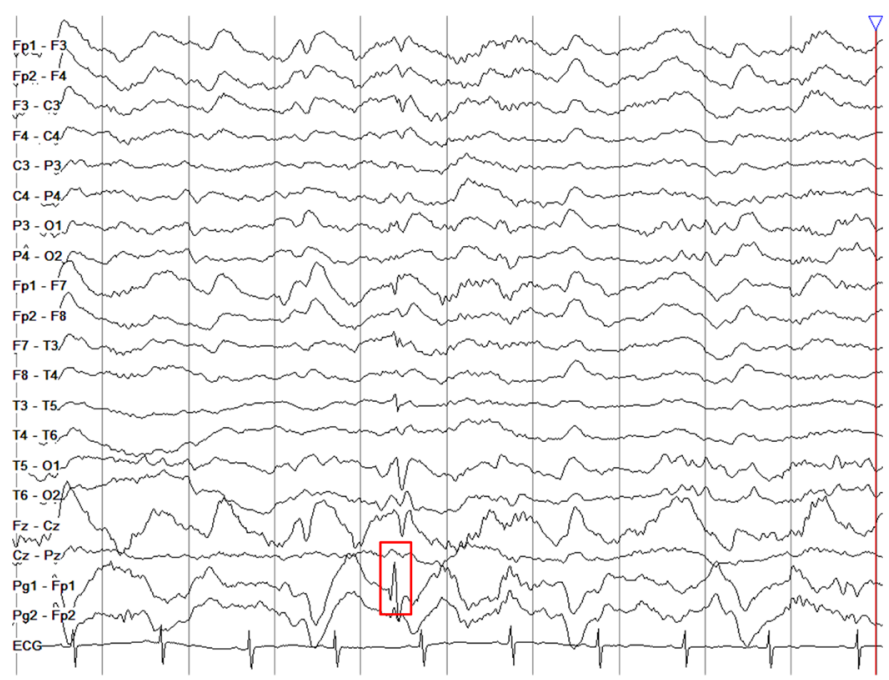

B

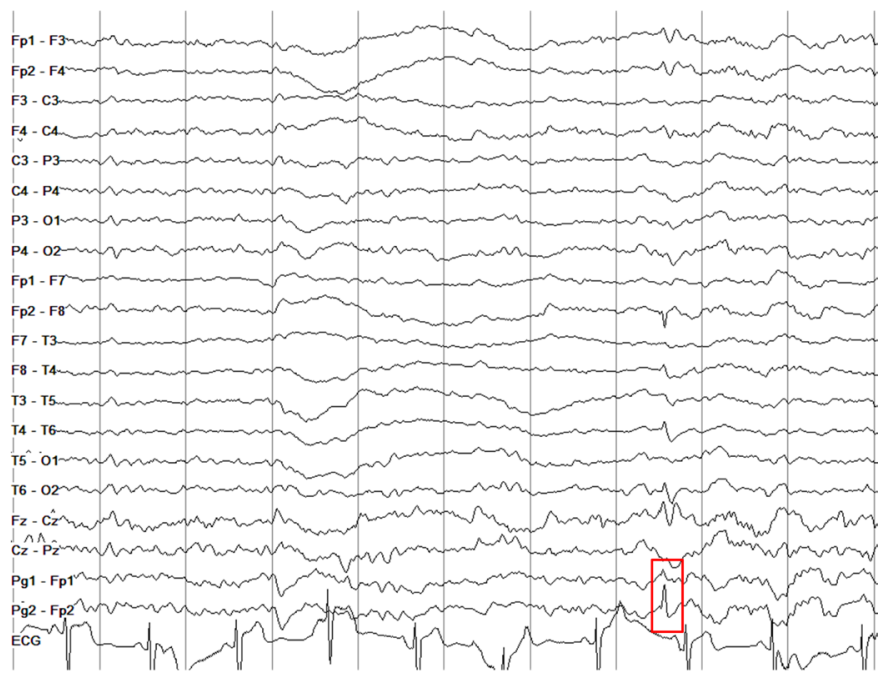

Figure 2 Ictal EEG of patients with TLES. Ictal discharge starts with bilateral spikes, spike and wave complex (SWC) activities on each electrode, and electrodes Pg1-Fp1 (left temporal pole) shows spike discharge (inside the red box) (A). Electrodes Pg2-Fp2 (right temporal pole) shows some spikes and SWC activities (inside the red box) (B).

males and eight females, age: $32.9 \pm 13.3$ ), nine patients with clinically diagnosed ONES (four males and five females, age: $39.8 \pm 20.8$ ), and 15 healthy controls (five male and ten females, age: $27.0 \pm 4.26$ ). All subjects underwent MRI and MRS examinations. TLES represents the most prevalent form of localization-related epilepsies. The diagnosis was based on the following criteria: (I) the region of interest (ROI) was in accordance with ictal onset zone owing to clinical features in consistence with seizures of temporal lobe origin and EEG (Figure 2), (II) the collected MRI and MRS confirmed qualitatively by experienced neuroradiology technicians to give diagnosis opinions, and then reviewed by authoritative clinical neurologists combining with clinical manifestations and electrophysiology to diagnose diseases. Clinically, all patients were diagnosed by means of clinical features, onset history, neurological exam, blood test, EEG, MRI and MRS. And demographic and clinical characteristic of subjects is given in Table 1 and Table 2. All patients were in the observation stage of hospitalization. After the habitual seizures of patients, they must be evaluated and confirmed by the neurologists, and these patients in postictal phase were immediately sent to the imaging center. The total acquisition time of both MRI and MRS was almost $1 \mathrm{~h}$.

\section{MRI}

MRI was performed on a clinical $1.5 \mathrm{~T}$ system (GE
SIGNA HDe Medical System) with the following imaging parameters: T1 fluid attenuated inversion recovery (T1 FLAIR): repetition time/echo time/inversion time (TR/ $\mathrm{TE} / \mathrm{TI})=1,800 / 24 / 750 \mathrm{~ms}$, matrix $=320 \times 192$, number of excitation $(\mathrm{NEX})=1$; fast relaxation fast spin echo T2 weighted imaging (FRFSE T2WI): TR/TE $=4,760 / 102$ ms, matrix $=320 \times 256$, NEX $=1$; T2 FLAIR: TR/TE/ $\mathrm{TI}=8,600 / 120 / 2,100 \mathrm{~ms}$, matrix $=288 \times 160, \mathrm{NEX}=1$; Diffusion-weighted imaging (DWI): b-value $=1,000 \mathrm{~s} / \mathrm{mm}^{2}$, $\mathrm{TR} / \mathrm{TE}=6,000 / 56 \mathrm{~ms}$, matrix $=128 \times 128, \mathrm{NEX}=2$. Common parameters common to all sequences: field of view $(\mathrm{FOV})=24 \mathrm{~cm} \times 24 \mathrm{~cm}$, slice thickness $=5 \mathrm{~mm}$, gap $=1.5 \mathrm{~mm}$. Figure $1 A, B$ show the MRI and MRS results of TLES patients. Figure $1 C$ shows the MRI and MRS results of a healthy subject. An example of negative MRI inspection while the MRS signal is abnormal in obvious inconsistency of NAA/Cr on both sides is presented.

\section{MRS}

Small temporal pole encephaloceles are now recognized for being a hidden cause of MRI-negative TLES (15). The most common abnormality reported in TLES patients is a reduction in levels of NAA or NAA/Cr (16). Abnormalities in these parameters have also been noted in the contralateral temporal lobe and in other lobes (17), and no significant difference between the two hemispheres 
Table 1 Demographic and clinical characteristic of patients with ONES

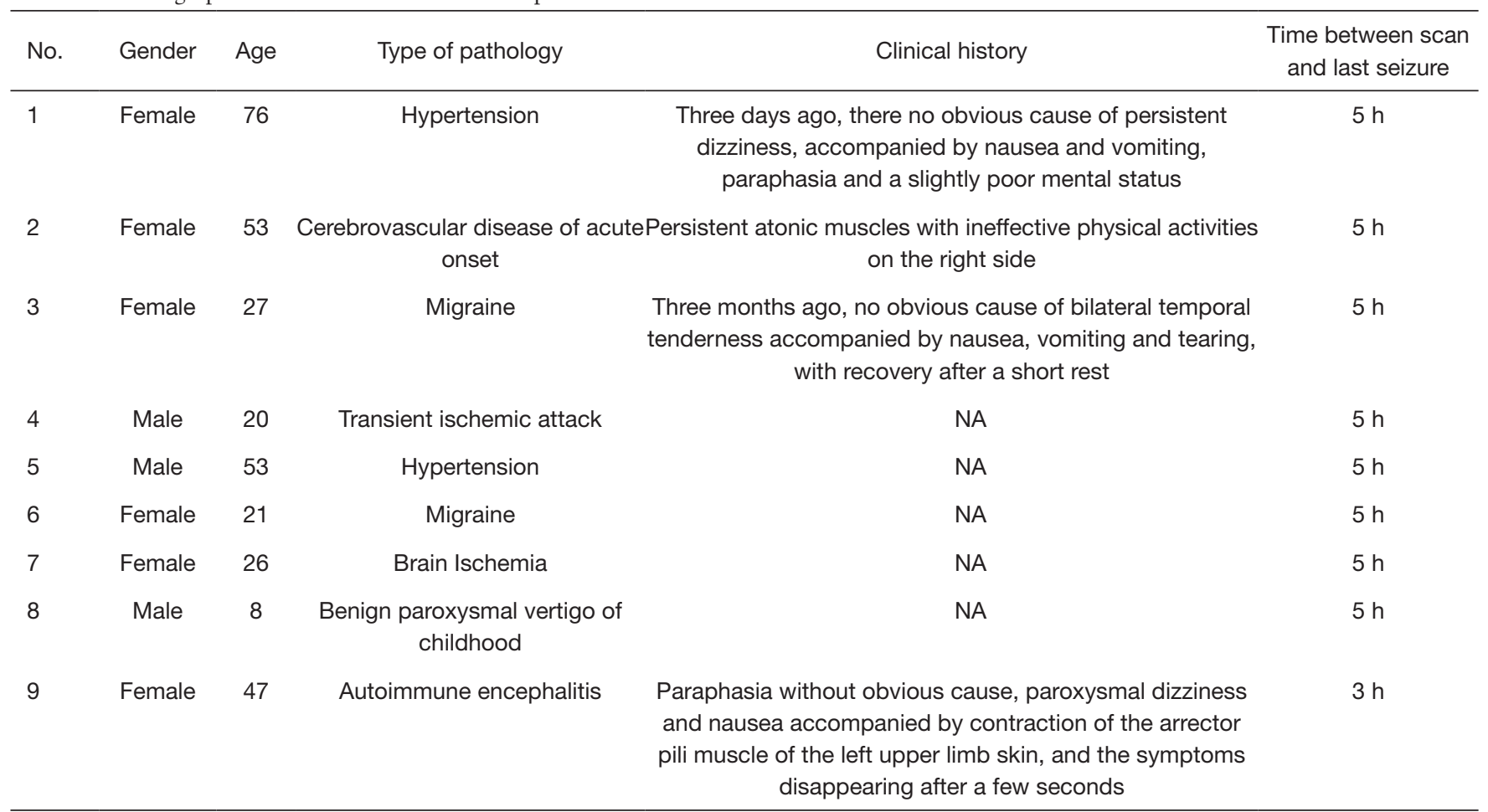

Note: "NA" represents the corresponding information was not available. ONES, organic non-epileptic seizures.

of the human brain (18). Accordingly, the ROI was set in the left and right temporal lobe regions. The single-voxel spectra were collected from the left temporal pole firstly and then the right. The location of the single-voxel spectral target volume was planned in high-resolution T2WI images. In addition, only neuroradiology technicians, who have at least five years of clinical experience, were allowed to manually place these ROIs. On the same scanner, MRS studies were acquired with imaging parameters: pointresolved spectroscopic sequence (PROBE-P), axial sampling plane, $\mathrm{FOV}=20 \mathrm{~mm} \times 20 \mathrm{~mm}$, the voxel thickness $=20 \mathrm{~mm}$, the chemical displacement imaging (CSI) layer thickness $=20 \mathrm{~mm}, \mathrm{NEX}=8$. The PROBE-P image $(\mathrm{TR} / \mathrm{TE}$ $=2,000 / 144 \mathrm{~ms}$ ) was used in the coronal view. The subjects underwent an MRS scan to acquire the metabolite spectrum results and then conduct a comparative test to determine the difference between ONES and TLES (Figure 3).

\section{Data statistical analysis}

\section{Data processing}

After the acquisition, the data were automatically processed in the default manner by using the MR spectroscopic post- processing software package (SAGE 7.1) built in the GE $1.5 \mathrm{~T}$ system. The technicians and authors did not perform any extra processing. To determine the relative concentration, integrations over ranges of chemical shifts are as follows: NAA 2.20-1.80 ppm, Cho 3.34-3.19 ppm and Cr 3.12-2.97 ppm. The following metabolites ratios were measured: NAA/Cr, $\mathrm{NAA} / \mathrm{Cho}, \mathrm{NAA} /(\mathrm{Cho}+\mathrm{Cr}), \mathrm{Cho} / \mathrm{Cr}$ (19).

\section{Data statistical analysis}

Statistical analyses were performed by the Mann-Whitney $\mathrm{U}$ test with age as covariate (20), and our data met the assumptions of the Mann-Whitney $\mathrm{U}$ test. Considering the influence of multiple comparisons on the $\mathrm{P}$ values, $\mathrm{P}$ values have been processed with the Bonferroni correction. The entire metabolic contents of NAA, Cho, and $\mathrm{Cr}$ were obtained by MRS, and NAA/Cr, NAA/Cho, NAA/(Cho $+\mathrm{Cr})$, Cho/Cr were calculated. Differences of statistical significance $(\mathrm{P}<0.05)$ were taken into consideration.

\section{Results}

The comparison between TLES group, ONES group, and healthy controls is shown in Figure 4. Two main points are 
Table 2 Demographic and clinical characteristic of patients with TLES

\begin{tabular}{|c|c|c|c|c|c|}
\hline No. & Gender & Age & Type of pathology & Clinical history & $\begin{array}{l}\text { Time between scan } \\
\text { and last seizure }\end{array}$ \\
\hline 1 & Male & 45 & Epilepsy & NA & $3 \mathrm{~h}$ \\
\hline 2 & Male & 58 & Epilepsy & $\begin{array}{c}\text { Suddenly during sleep three months ago with a poor response. Three } \\
\text { days ago, awake for a long time, left limb weakness. Difficulty walking } \\
\text { one day ago, no history of allergies }\end{array}$ & $3 \mathrm{~h}$ \\
\hline 4 & Female & 21 & Epilepsy & NA & $1 \mathrm{~h}$ \\
\hline 5 & Male & 39 & Epilepsy & $\begin{array}{l}\text { Recurring limb tic, unconsciousness for } 39 \text { years, } 3 \text { attacks per year, } \\
\text { difficulty falling asleep one day before }\end{array}$ & $1 \mathrm{~h}$ \\
\hline 6 & Female & 61 & Epilepsy & Recurrent limb tic & $1 \mathrm{~h}$ \\
\hline 9 & Male & 23 & Epilepsy & NA & $3 \mathrm{~h}$ \\
\hline 10 & Female & 39 & Epilepsy & NA & $3 \mathrm{~h}$ \\
\hline 11 & Male & 30 & Epilepsy & NA & $3 \mathrm{~h}$ \\
\hline 12 & Female & 21 & Epilepsy & $\begin{array}{c}\text { Five years ago, no obvious cause for sudden limb twitching, both upper } \\
\text { limbs were bent, involuntary consciousness, eyes turned up, teeth } \\
\text { closed, and then repeated attacking three times. The last attack with the } \\
\text { same symptoms two days ago }\end{array}$ & $3 \mathrm{~h}$ \\
\hline 13 & Female & 26 & Epilepsy & NA & $3 \mathrm{~h}$ \\
\hline 18 & Male & 39 & Epilepsy & $\begin{array}{c}\text { Two months ago, no obvious cause for paroxysmal loss of consciousness } \\
\text { and limb twitching, and each lasting about a few minutes. Saliva and } \\
\text { a little vomit at the corners of the mouth after waking up, and general } \\
\text { fatigue }\end{array}$ & $3 \mathrm{~h}$ \\
\hline 19 & Male & 14 & Epilepsy & NA & $3 \mathrm{~h}$ \\
\hline 20 & Female & 12 & Epilepsy & NA & $3 \mathrm{~h}$ \\
\hline 21 & Female & 22 & Epilepsy & NA & $3 \mathrm{~h}$ \\
\hline 22 & Male & 14 & Epilepsy & NA & $3 \mathrm{~h}$ \\
\hline 23 & Male & 46 & Epilepsy & NA & $3 \mathrm{~h}$ \\
\hline
\end{tabular}

Note: "NA" represents the corresponding information was not found. TLES, temporal lobe epileptic seizures. 


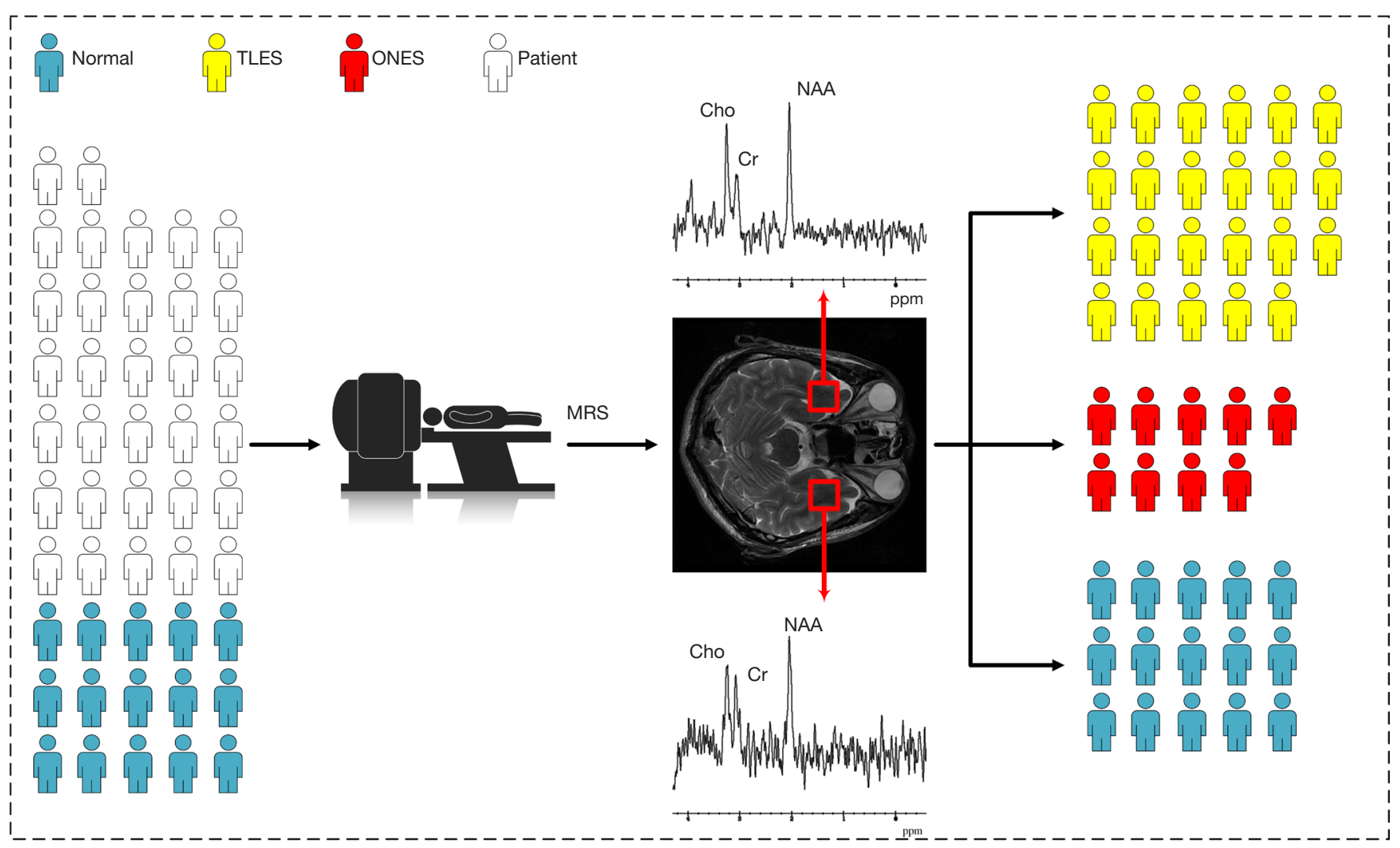

Figure 3 The process diagram of controlled trial by MRS: placement of ROI over the left and right part at the temporal pole regions of patient $\mathrm{M}$ with epilepsy, obtaining the contents of $\mathrm{N}$-acetyl-aspartate, Creatine, and Choline.

identified: Three significant differences in metabolite ratios existed between TLES group and healthy controls, whereas only one existed between TLES and ONES groups.

\section{$\mathrm{NAA} / \mathrm{Cr}$}

The NAA/Cr ratio in left temporal pole of TLES group in postictal phase was lower evidently in comparison to healthy controls (TLES $1.422 \pm 0.037$, Healthy controls $1.897 \pm 0.047, \mathrm{P}=0.000)$. And this ratio in left temporal pole of ONES group in postictal phase was lower significantly in comparison with healthy controls. The $\mathrm{NAA} / \mathrm{Cr}$ ratio in left temporal pole of TLES group was statistically different from ONES group (TLES $1.422 \pm 0.037$, ONES $1.640 \pm 0.061, \mathrm{P}=0.012)$. The $\mathrm{P}$ value between ONES group and healthy controls was 0.006 (Table 3).

\section{NAA/Cho}

In postictal phase, the NAA/Cho ratio in left temporal pole of TLES group was not statistically different from
ONES group $(\mathrm{P}=0.384)$ but healthy controls $(\mathrm{P}=0.000)$ (TLES $1.065 \pm 0.039$, ONES $1.181 \pm 0.064$, healthy controls $1.376 \pm 0.049)$. NAA/Cho ratio in left temporal pole of TLES group was lower than ONES group and healthy controls in postictal phase. The NAA/Cho ratio in left temporal pole of ONES group was not statistically different from healthy controls $(\mathrm{P}=0.061)$ (Table 3).

\section{$\mathrm{NAA} /(\mathrm{Cbo}+\mathrm{Cr})$}

There existed a significant difference between left temporal pole of TLES group in postictal phase and healthy controls in this ratio $(\mathrm{P}=0.000)$. This ratio in left temporal pole of TLES group was close to that of ONES group (TLES $0.606 \pm 0.018$, ONES $0.686 \pm 0.030$ ). No significant difference was revealed between TLES group and ONES group in postictal phase $(\mathrm{P}=0.080)$. In postictal phase, the $\mathrm{NAA} /(\mathrm{Cho}$ $+\mathrm{Cr}$ ) ratio in left temporal pole of ONES group was lower substantially compared with healthy controls, i.e., ONES $0.686 \pm 0.030$, healthy controls $0.796 \pm 0.023, \mathrm{P}=0.016$, as shown in Table 3. 


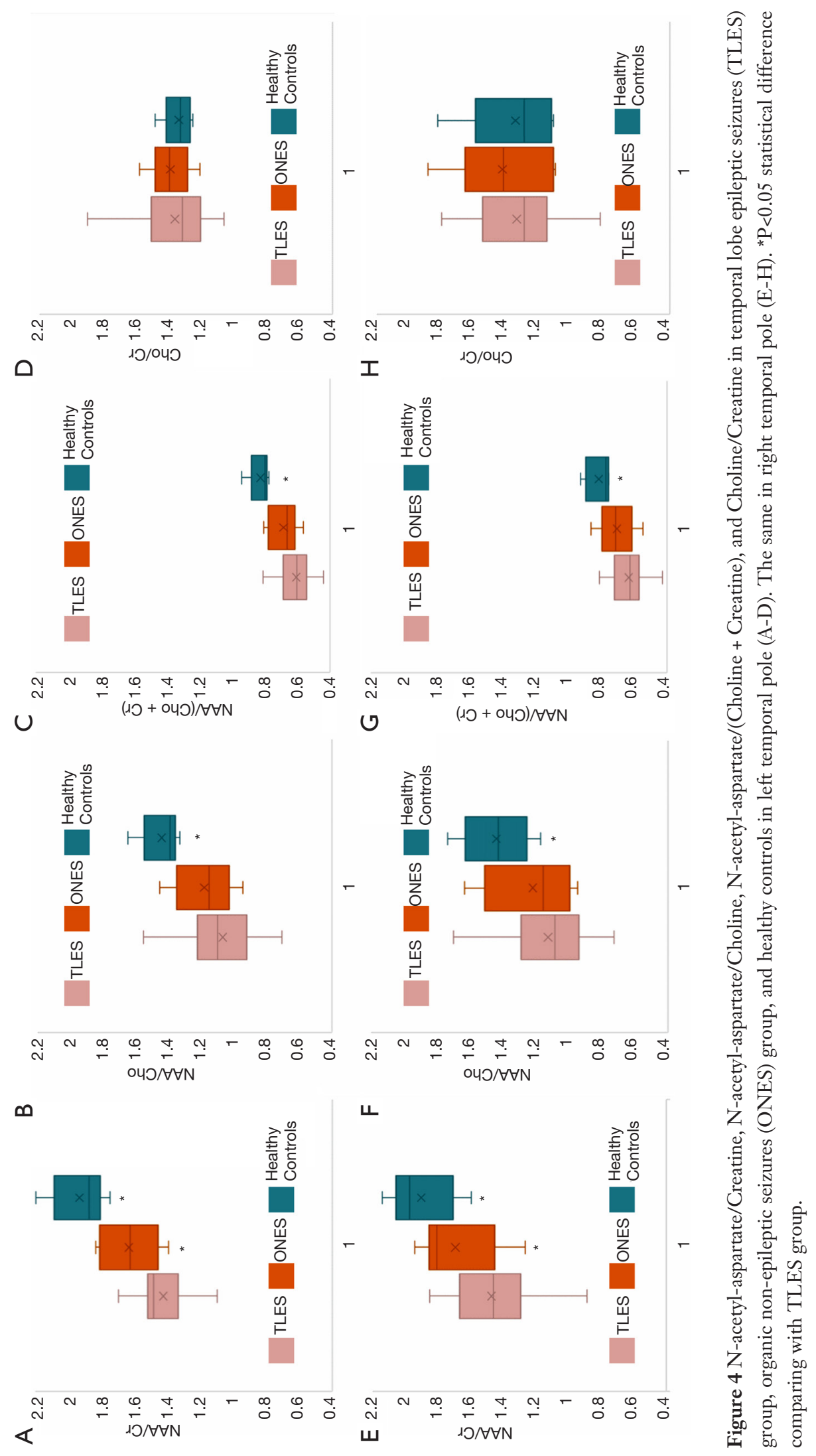


Table 3 Comparison of left temporal pole between TLES group, ONES group and healthy controls (age as covariate)

\begin{tabular}{|c|c|c|c|c|c|c|}
\hline Metabolites ratio & \multicolumn{3}{|c|}{ Ratio } & \multicolumn{3}{|c|}{$P$ value } \\
\hline $\mathrm{NAA} / \mathrm{Cr}$ & $1.422 \pm 0.037$ & $1.640 \pm 0.061$ & $1.897 \pm 0.047$ & 0.012 & 0.000 & 0.006 \\
\hline NAA/Cho & $1.065 \pm 0.039$ & $1.181 \pm 0.064$ & $1.376 \pm 0.049$ & 0.384 & 0.000 & 0.061 \\
\hline $\mathrm{NAA} /(\mathrm{Cho}+\mathrm{Cr})$ & $0.606 \pm 0.018$ & $0.686 \pm 0.030$ & $0.796 \pm 0.023$ & 0.080 & 0.000 & 0.016 \\
\hline
\end{tabular}

TLES, temporal lobe epileptic seizures; ONES, organic non-epileptic seizures.

Table 4 Comparison of right temporal pole between TLES group, ONES group and healthy controls (age as covariate)

\begin{tabular}{|c|c|c|c|c|c|c|}
\hline $\begin{array}{l}\text { Metabolites } \\
\text { ratio }\end{array}$ & \multicolumn{3}{|c|}{ Ratio } & \multicolumn{3}{|c|}{$\mathrm{P}$ value } \\
\hline $\mathrm{NAA} / \mathrm{Cr}$ & $1.470 \pm 0.052$ & $1.687 \pm 0.084$ & $1.901 \pm 0.064$ & 0.023 & 0.000 & 0.160 \\
\hline NAA/Cho & $1.125 \pm 0.049$ & $1.223 \pm 0.081$ & $1.371 \pm 0.062$ & 0.922 & 0.010 & 0.475 \\
\hline $\mathrm{NAA} /(\mathrm{Cho}+\mathrm{Cr})$ & $0.631 \pm 0.022$ & $0.702 \pm 0.035$ & $0.792 \pm 0.027$ & 0.276 & 0.000 & 0.162 \\
\hline
\end{tabular}

TLES, temporal lobe epileptic seizures; ONES, organic non-epileptic seizures.

\section{$\mathrm{Cbo} / \mathrm{Cr}$}

We noted that no statistical difference existed in left temporal pole of the three groups in postictal phase (TLES $1.365 \pm 0.038$, ONES $1.402 \pm 0.061$, healthy controls $1.384 \pm 0.047$ ) (Table 3).

For TLES group in comparison with ONES group and TLES group in comparison with healthy controls, the statistical differences of the four ratios (NAA/Cr, NAA/ Cho, NAA/(Cho $+\mathrm{Cr}), \mathrm{Cho} / \mathrm{Cr})$ in right temporal pole was the same as that in left temporal pole (Table 4). NAA/ $\mathrm{Cr}$ and $\mathrm{NAA} /(\mathrm{Cho}+\mathrm{Cr})$ in left temporal pole of ONES group in postictal phase were statistically different with healthy controls $(\mathrm{P}=0.006,0.016)$. However, NAA/Cr and $\mathrm{NAA} /(\mathrm{Cho}+\mathrm{Cr})$ in right temporal pole of ONES group in postictal phase were not statistically different with healthy controls $(\mathrm{P}=0.160,0.162)$.

The difference between TLES group and ONES group was reflected only on NAA/Cr, which has not been found in the references to the best of our knowledge. Besides, $\mathrm{NAA} / \mathrm{Cr}, \mathrm{NAA} / \mathrm{Cho}$, and NAA/(Cho + Cr) ratios in temporal pole of TLES group in postictal phase were lower compared with healthy controls, suggesting a decrease as demonstrated by a previous study (20).

\section{Discussion}

Non-epileptic seizures (NES) resemble epileptic seizures (ES) in outward appearance, even though their causes are very different. Differences in metabolites are common in brain research. Previous studies on the metabolites of epilepsy mainly focused on NAA, Cr, and Cho. In neuro histochemical studies (1), NAA, localized in perikaryal, axons, and dendrites of neurons, is synthesized mainly in neuronal mitochondria. Another metabolite, $\mathrm{Cr}$, is a reliable marker of brain energy metabolism and is considered as a marker of membrane integrity (1). Moreover, previous studies indicate that NAA concentration decreases during medial TLES (1), the mobility of choline increases in postictal phase of seizures $(14,21)$. Decreased NAA was present in the temporal lobe of TLES patients, indicating that the change was characteristic of the focus of the seizures (Figure 4). Low NAA may reflect the degree of seizure discharge originating in the temporal lobe. The previous study (20) showed statistically significant decreases in NAA/Cr, NAA/Cho and NAA/(Cho + Cr) immediately after ictus in TLES group as compared with control data and those ratios in TLES group in interictal phase. In contrast, no statistically significant difference was presented 
between TLES group in interictal phase and control data. Our result revealed that NAA/Cr, NAA/Cho, and NAA/ $(\mathrm{Cho}+\mathrm{Cr})$ ratios in temporal pole of TLES group in postictal phase were lower compared with healthy controls, suggesting a decrease demonstrated by a previous study (20). The majority of ONES (22) are caused by traumatic experiences, developmental factors, vasovagal mechanisms, or other less benign cardiac etiologies.

While no single diagnostic method works perfectly to determine whether loss of consciousness with associated convulsions results from ES or NES, accurate metabolites measurement could be an efficient diagnostic tool, and MRS will be helpful. MRS is used to investigate seizures, which displays highly aberrant metabolism. It is wise to use MRS to locate the focus area and detect brain metabolites (23).

The noticeable statistical difference between TLES group and ONES group in postictal phase is in NAA/ $\mathrm{Cr}$ ratio. Concerning TLES group in postictal phase, the diagnostic items that differentiated this group from healthy controls were statistical differences in the ratio of these three metabolites [NAA/Cr, NAA/Cho, NAA/(Cho + $\mathrm{Cr})$ ] $(14,20)$. Previous studies have shown that NAA decreased and Cho increased in TLES patients in postictal phase compared with the healthy controls (20).

At present, the brain metabolites researches on NES are still very rare. However, when measured in the first $2 \mathrm{~h}$ after the index event, serum lactate level has a high clinical utility in the differential diagnosis of ES and NES (24). And epidemiological evidence implies that epilepsy and ONES may be comorbid conditions, such that the existence of one condition increases the risk of the other (25). Our result reported in this work provides a new idea for TLES and ONES. Namely, NAA/Cr in the postictal phase can be a reference value for distinguishing TLES from ONES, and MRS detection has excellent potential in TLE related metabolites content changes. If the data to be processed is too large, using artificial intelligence to analyze MRS may be a wise choice $(26,27)$.

However, there are still some limitations to this study. When comparing ONES group, we can only ensure NAA/ Cr ratio in our study is statistically different from that in TLES group. What's more, many kinds of neurological diseases can affect the metabolism of NAA and Cr. Therefore, when faced with other diseases, there is no guarantee that $\mathrm{NAA} / \mathrm{Cr}$ ratio is the same as that of nonepileptic patients involved in this research. Besides, the hypothesis needs to be tested in a prospective manner, with a larger sample size of ONES testers, to result in a firmer conclusion.

In conclusion, we found that TLES patients and ONES patients had NAA/Cr differences in the postictal phase. This finding suggests MRS can be an effective method in diagnosing or studying brain diseases like ES and NES. This result requires prospective verification of a large number of TLES and ONES patients to promote the development of the medical problem of epilepsy.

\section{Acknowledgments}

We sincerely thank all participants in this project and all of our collaborators in the second affiliated hospital of Xiamen Medical College.

Funding: This work was supported in part by National Natural Science Foundation of China [grant number 61971361, 61871341, 61811530021 and U1632274], National Key R\&D Program of China [grant number 2017YFC0108703], Natural Science Foundation of Fujian Province of China [grant number 2018J06018 and 2019J01047], Fundamental Research Funds for the Central Universities [grant number 20720180056 and 20720200065], Fujian Provincial Health Young and Middle-aged Key Talents Training Project [grant number 2020GGB067], Fujian Health Education Joint Research Project [grant number 2019-WJ-31], Xiamen University Nanqiang Outstanding Talents Program, Xiamen Medical and Health Guidance Project from the Science and Technology Bureau of Xiamen [grant number $3502 Z 20199064$ and 3502Z20144052].

\section{Footnote}

Conflicts of Interest: All authors have completed the ICMJE uniform disclosure form (available at http://dx.doi. org/10.21037/qims-20-1147). The authors have no conflicts of interest to declare.

Ethical Statement: The authors are accountable for all aspects of the work in ensuring that questions related to the accuracy or integrity of any part of the work are appropriately investigated and resolved. All procedures performed in studies involving human participants were in accordance with the ethical standards of the institutional and/or national research committee(s) and with the Helsinki Declaration (as revised in 2013). Written informed consent was obtained from the patient.

Open Access Statement: This is an Open Access article 
distributed in accordance with the Creative Commons Attribution-NonCommercial-NoDerivs 4.0 International License (CC BY-NC-ND 4.0), which permits the noncommercial replication and distribution of the article with the strict proviso that no changes or edits are made and the original work is properly cited (including links to both the formal publication through the relevant DOI and the license). See: https://creativecommons.org/licenses/by-nc-nd/4.0/.

\section{References}

1. Mueller SG, Suhy J, Laxer KD, Flenniken DL, Axelrad J, Capizzano AA, Weiner MW. Reduced extrahippocampal NAA in mesial temporal lobe epilepsy. Epilepsia 2002;43:1210-6.

2. Winston GP. The role of magnetic resonance imaging techniques in the diagnosis, surgical treatment and biological understanding of epilepsy. Quant Imaging Med Surg 2015;5:186-7.

3. Wiebe S, Blume WT, Girvin JP, Eliasziw M; Effectiveness and Efficiency of Surgery for Temporal Lobe Epilepsy Study Group. A randomized, controlled trial of surgery for temporal-lobe epilepsy. N Engl J Med 2001;345:311-8.

4. Kotsopoulos IAW, de Krom MCTFM, Kessels FGH, Lodder J, Troost J, Twellaar M, van Merode T, Knottnerus AJ. The diagnosis of epileptic and non-epileptic seizures. Epilepsy Res 2003;57:59-67.

5. Francis P, Baker GA. Non-epileptic attack disorder (NEAD): a comprehensive review. Seizure 1999;8:53-61.

6. Mellers JDC. The approach to patients with "non-epileptic seizures". Postgrad Med J 2005;81:498-504.

7. Patel M, Satishchandra P, Saini J, Bharath RD, Sinha S. Eating epilepsy: Phenotype, MRI, SPECT and video-EEG observations. Epilepsy Res 2013;107:115-20.

8. Suhy J, Laxer KD, Capizzano AA, Vermathen P, Matson GB, Barbaro NM, Weiner MW. 1H MRSI predicts surgical outcome in MRI-negative temporal lobe epilepsy. Neurology 2002;58:821-3.

9. van Graan LA, Lemieux L, Chaudhary UJ. Methods and utility of EEG-fMRI in epilepsy. Quant Imaging Med Surg 2015;5:300-12.

10. Liu J, Meng F, Liu Z. Seizure-related adverse events during video-electroencephalography monitoring. Epileptic Disord 2012;14:51-6.

11. Agrawal S, Turco L, Goswami S, Faulkner M, Singh S. Yield of monitoring in an adult epilepsy monitoring unit (P2.097). Neurology 2015;84:P2.097.

12. Maton B, Gilliam F, Sawrie S, Faught E, Hugg J,
Kuzniecky R. Correlation of scalp EEG and 1H-MRS metabolic abnormalities in temporal lobe epilepsy. Epilepsia 2001;42:417-22.

13. Pan JW, Kuzniecky RI. Utility of magnetic resonance spectroscopic imaging for human epilepsy. Quant Imaging Med Surg 2015;5:313-22.

14. Flügel D, McLean MA, Simister RJ, Duncan JS. Magnetisation transfer ratio of choline is reduced following epileptic seizures. NMR Biomed 2006;19:217-22.

15. Muhlhofer W, Tan YL, Mueller SG, Knowlton R. MRInegative temporal lobe epilepsy-What do we know? Epilepsia 2017;58:727-42.

16. Mueller SG, Laxer KD, Barakos JA, Cashdollar N, Flenniken DL, Vermathen P, Matson GB, Weiner MW. Metabolic characteristics of cortical malformations causing epilepsy. J Neurol 2005;252:1082-92.

17. Simister RJ, McLean MA, Salmenpera TM, Barker GJ, Duncan JS. The effect of epileptic seizures on proton MRS visible neurochemical concentrations. Epilepsy Res 2008;81:36-43.

18. Nagae-Poetscher LM, Bonekamp D, Barker PB, Brant LJ, Kaufmann WE, Horská A. Asymmetry and gender effect in functionally lateralized cortical regions: a proton MRS imaging study. J Magn Reson Imaging 2004;19:27-33.

19. Mazaheri Y, Shukla-Dave A, Goldman DA, Moskowitz CS, Takeda T, Reuter VE, Akin O, Hricak H. Characterization of prostate cancer with MR spectroscopic imaging and diffusion-weighted imaging at 3 Tesla. Magn Reson Imaging 2019;55:93-102.

20. Fadaie F, Mobarakeh NM, Fesharaki SS, Harirchian MH, Kharazi HH, Rad HS, Habibabadi JM. 1H-MRS metabolite's ratios show temporal alternation in temporal lobe seizure: Comparison between interictal and postictal phases. Epilepsy Res 2016;128:158-62.

21. Wellard RM, Briellmann RS, Prichard JW, Syngeniotis A, Jackson GD. Myoinositol abnormalities in temporal lobe epilepsy. Epilepsia 2003;44:815-21.

22. Devinsky O, Gazzola D, LaFrance WC. Differentiating between nonepileptic and epileptic seizures. Nat Rev Neurol 2011;7:210-20.

23. Xu MY, Ergene E, Zagardo M, Tracy PT, Wang HP, Liu WC, Machens NA. Proton MR spectroscopy in patients with atructural MRI-negative temporal lobe epilepsy. J Neuroimaging 2015;25:1030-7.

24. Doğan EA, Ünal A, Ünal A, Erdoğan Ç. Clinical utility of serum lactate levels for differential diagnosis of generalized tonic-clonic seizures from psychogenic nonepileptic seizures and syncope. Epilepsy Behav 2017;75:13-7. 
25. Rogawski MA, Löscher W. The neurobiology of antiepileptic drugs for the treatment of nonepileptic conditions. Nat Med 2004;10:685-92.

26. Qu X, Huang Y, Lu H, Qiu T, Guo D, Agback T, Orekhov V, Chen Z. Accelerated Nuclear Magnetic Resonance
Spectroscopy with Deep Learning. Angew Chem Int Ed Engl 2020;59:10297-300.

27. Chen D, Wang Z, Guo D, Orekhov V, Qu X. Review and Prospect: Deep Learning in Nuclear Magnetic Resonance Spectroscopy. Chemistry 2020;26:10391-401.

Cite this article as: Liu D, Yang $\mathrm{Y}$, Chen D, Wang Z, Guo D, Bao L, Dong J, Wang X, Qu X. Brain metabolic differences between temporal lobe epileptic seizures and organic non-epileptic seizures in postictal phase: a retrospective study with magnetic resonance spectroscopy. Quant Imaging Med Surg 2021;11(8):3781-3791. doi: 10.21037/qims-20-1147 